\title{
A Time Switching System Using Atmega328 Microcontroller towards Solving Problem of Electrical Power Wastage
}

\author{
Salako Emmanuel Adekunle \\ Department of Computer Science, FCT College of Education, Zuba-Abuja, Nigeria \\ Email: kunlesky2@gmail.com
}

Received: 14 November 2018; Accepted: 22 May 2019; Published: 08 June 2019

\begin{abstract}
The wastage of electrical power cannot be over-emphasized in FCT College of Education, ZubaAbuja as many lighting bulbs, street-lights, electrical fans are always ON even when not in use. The college community is characterized by electrical power wastage. However, the motivation for this research was to curtail the electrical power wastage and reduce the high cost of electricity. This research was designed to control ON and OFF time of any electrical appliance connected to its output and could as well be used as a digital clock. The objective of this research was to control the ON and OFF time of air conditioning. The design included a microcontroller (ATMEGA328) that was programmed to achieve the timing operation. The Light Emitting Diode (LED) displayed the ton (Time ON) and the toff (Time OFF); four keys set the hour and the minutes; and the relay was activated whenever the time set elapsed, causing the air conditioning to be energized/dis-energized automatically. A time of 3:19 was set to test the ON switching. An air conditioning connected to the developed system was activated at exactly 3:19. Also, a time of 5:57 was set to de-activate the already ON electric bulb. The electric bulb was switched OFF at exactly 5:57. The developed switching system was tested and satisfactorily switched ON and OFF air conditioning as desired and pre-set by the user.
\end{abstract}

Index Terms-Atmega328 Microcontroller, Design, Implementation, Switching and Time.

\section{INTRODUCTION}

A switch is a device that interrupts the flow of an electric current in a circuit either automatically or manually. A switch is an electronic device that controls or directs the flow of electric current in a circuit. Typically, a switch allows or disallows the flow of electric current to a connected load. A switch is a binary device that either completely ON (CLOSE) or completely OFF (OPEN) an electrical circuit. There are basically two types of switches. These include mechanical and electronic switches. A mechanical switch makes a physical contact between two metal plates for the current to flow and separate from each other plate to interrupt the flow of current. On the other hand, an electronic switch is a device that switches an electrical circuit, interrupting the current or diverting it from one conductor to another. All mechanical switches are manually operated while electronic switches are automatically operated using a solid state device such as a microcontroller or a microprocessor. Generally, electronic switches are fasters in response than the mechanical switches. Among the electronic switches is a timing switch that controls the flow of an electric current on the basis of pre-set time by the user. A timing switch is an electronic device that controls the connection and disconnection of electrical appliances based on pre-set time. According to Reference [4] a timing switch is paramount in areas where the measurement of time is fundamental to successful operation without unpredictable human input. It is quite evident that for proper organization, events should be done in a specific time (Ref. [6]). A good timing switch is tasked to activate ON or OFF an event at a pre-defined time. It is quite useful in everyday life. Some advanced electronic timing switches are commonly used for military purposes. A timing switch is of great importance in microwave ovens, computer systems, school laboratory experiments, electrical heaters, to mention but a few.

This research design was involved two fundamental aspects of computer technology; the software design, and the hardware design. It was designed around a microcontroller chip (ATMEGA328). This is a timer that gives adjustable timing controls of appliances' operations. The developed time switching (TS) system turned AC load ON or OFF with preset time and it was programmed using $\mathrm{C}$ programming language. According to Reference [7] $\mathrm{C}$ programming language as one of the high-level programming languages has now become a widely used professional language for various beneficial values. These values include: easy to learn and write, use English-like words and symbols, structured language that is problemoriented, it produces efficient programs, it can handle low and high-level activities and it can be compiled on a variety of computer platforms.

The uniqueness of this switching system using ATMEGA328 microcontroller was in its functionalities to automatically switch $\mathrm{ON}$ an initially OFF electrical 
appliance and at the same time to automatically switch OFF initially ON appliance connected to its output after a preset time. The developed system was relatively cheap, reliable and easy to operate when comparing to power wastage and cost of electricity.

\section{RESEARCH MOTIVATION}

\section{A. Statement of the Problem}

It has been observed at FCT College of Education, Zuba community that government officers leaving office's electrical appliances such as fans, airconditioning $(\mathrm{AC})$, refrigerators, television set and radio set $\mathrm{ON}$ after closing hours. This poor attitude had cost the institution millions of naira to settle the electricity bills and embarrassing the institution as the Power Holding of Nigeria (PHCN) officers disconnected the power supply.

The College community is characterized by electrical power wastage as many lighting bulbs, street-lights, electrical fans are always ON even when not needed. It is on these identified problems that this research focused on the design and implementation of a time switching (TS) system using the ATMEGA328 microcontroller. The time switching (TS) system had the capability to control the $\mathrm{ON}$ and OFF states of any electrical appliance connected to its output based on the pre-set time.

\section{B. Research Justification}

This research would help:

1. Graduates would be creative and self-employed,

2. Generation revenue to the government as youths that have electronic shops selling the developed time switching system is taxed;

3. The problem of electrical power wastage could be tackled successfully,

4. The cost of electricity bill payment by powering the appliances OFF when not in use would be solved.

\section{Research Objectives}

The specific objectives of this research are to:

1. design of a time switching (TS) system using an atmega328 microcontroller

2. implement the designed time switching system

3. test the implemented time switching system

\section{LITERATURE REVIEW}

In the system, Reference [3] designed and built a circuit which mainly met the requirement of controlling the house appliances through any remote control device that was portable in the periphery of the room. The system was developed around a microcontroller (89c52) and IR remote transmitter. The developed system was able to control a load of excess energy from a remote area. A password to operate the system was also included. However, missing the remote control and obstruction of the signal were identified as problems to this design. Also, if the users could not remember the password, how to control the electrical load and prevent electrical power wastage becomes a problem. However, this new time switching system has the capability to store the pre-set time in an ATMEGA328 memory, and there was no problem of signal obstruction.

In Reference [2] a switching system was developed. The aim was to control electrical home appliances like fan, electric bulb using clap. A PIC18F2550 microcontroller and Adafruit TPA2012 (audio amplifier) were used to receive an input command from the users through a clap to control the electrical appliance. The developed system was able to control an electrical appliance. There was the likelihood of forgetting to clap so as to switch OFF the electrical appliances after use. Also, the PIC18F2550 microcontroller consumes more power and generates more heat than the ATMEGA328 microcontroller. However, the developed switching system would not require a clap rather it would operate the electrical appliance based on the pre-set $\mathrm{ON}$ and OFF times by the users.

According to Reference [5] energy consumption especially electricity was considered one of the most serious problems in households these days. It was because the amount of electricity consumed was more than the amount people actually need. This meant that there was an overuse of electricity which resulted from the inconvenience of moving to the switch to turn OFF the lighting point or any appliances and it was often that closing the light was forgettable. Reference [5] developed a switching device to turn appliances $\mathrm{ON}$ and $\mathrm{OFF}$ through the Internet on smart devices such as smartphones and tablets. The result indicated that the system was very effective with an uninterrupted connection. However, the system was ineffective where there were Internet connectivity problems and was not cost effective as smartphones are not cheap. This developed time switching system was cheaper than Reference [5] system as an Internet connection would not be required.

Reference [1] designed a microcontroller based infrared (IR) control of home appliances. The device was able to control a load of high power rating from a remote area. Also, any appliance could be made password protected through this design. However, missing of remote control and obstruction of the signal were identified as problems to this design. Also, if the users could not remember the password, how to control the electrical load and prevent electrical power wastage becomes a problem. However, this new time switching system has the capability to store the pre-set time in an ATMEGA328 memory, and there was no problem of signal obstruction.

Reference [8] designed a single phase changeover with security light. The system consisted of a sensing phase, a logic control phase and switch relays to achieve the smooth transition between the main power supply and the auxiliary power supply as well as controlling security lights. The system was tested and results showed uninterrupted power supply to the desired appliances. 
However, the system of [8] could not control the switching ON and OFF times as desired by the users. The lighting points were still on even not needed causing power wastage. This new time switching system controls both $\mathrm{ON}$ and $\mathrm{OFF}$ times of any electrical appliance as desired and pre-set by the users.

Reference [9] developed an automatic change over switch. In the research, basic electronic components (resistors, capacitor, controller) were used to implement the changeover switch. When there was a power failure from the main supply, the developed system was able to switch ON a standby generator and transfer the electrical load to the generator and vice versa when power was restored. The switching time was calculated and tested to be about $0.88 \mathrm{~ms}$. However, the system of [9] was not technically suitable to solve the problem of power wastage. What happen when the use of generator is not needed? By the design of [9], a standby generator would frequently switched $\mathrm{ON}$ whenever there is no power supply from the main supply. This implies that when power is not needed, a standby generator is $\mathrm{ON}$ and power wastage is inevitable. This new design would technically tackle the problem of power wastage in any institution and home as times to operate any connected electrical appliances are controlled by the pre-set or predefined time of users thereby controlling the power supply.

In [11], a constant power supply was designed and developed to automatically activate a generator when there was no power from the main source while [12] designed and developed a 3-phase automatic changeover system that could detect phase failure and under-voltage thereby changing over to the alternative power supply. In [11] and [12], there was no time that regulates the operation of the developed system. This new design would technically tackle the problem of power wastage as times to operate any connected electrical appliances are controlled by the pre-set or pre-defined time of users thereby controlling the power supply which could also manually adjusted for specific reason and operation.

In [13], an automatic changeover and sequential system was developed to eliminate the need for manual changeover by the users while [14] designed and implemented a microcontroller based automatic power changeover with artificial intelligence for automatic switching. There two sensors for public power supply and standby generator. The system was tested with results indicated a change of power supply from public to standby generator. This could not solve problem of power wastage because there was still power supply even when not need. Similarly [15] developed an automatic 3-Phase Selector. The aim of the system was to select a particular phase with electrical power supply. Similarly, [16] developed an Automatic Transfer Switch (ATS) for a Three Phase Power Generator. The electronic components used included an electromechanical relay, voltage monitoring, delay timer and contactors. In [13], [14], [15] and [16], time to operate any electrical load was the major factor to switch ON and OFF. Since, time to operate the electrical load was not considered in [13], [14], [15] and [16], there no way electrical power wastage could be solved. This new research would help in reducing electrical wastage thereby reducing electrical cost which in turn increases income for maximum productivity. In all situations, electrical signals to operate electrical appliances needed to be controlled. This new design would technically tackle the problem of power wastage in any institution and home as times to operate any connected electrical appliances are controlled by the pre-set or pre-defined time of users thereby controlling the power supply.

Reference [10] designed and implemented a three phase change over switch using contactors, phase failure relays and change-over delay mechanism. Experimental results indicated that the system changed from one phase to another phase when there was power supply. However, the system did not solve the problem of power supply as consumption electrical power is inevitable even when not needed. This new research tends to provide solution to the problem of electrical wastage, thereby increasing efficient utilization of power supply through proper management.

\section{RESEARCH METHODOLOGY}

The design of this research was fundamentally divided into two categories: hardware design and software development.

\section{A. Hardware Design}

The hardware design involved drawing and simulation of relevant electronic components to achieve the stated objectives of this research. However, the block diagram of the research is illustrated in Figure 1. There were six (6) functional modules in the design: the power supply, controller, the digit display, digit switch, keys and the activation modules. 


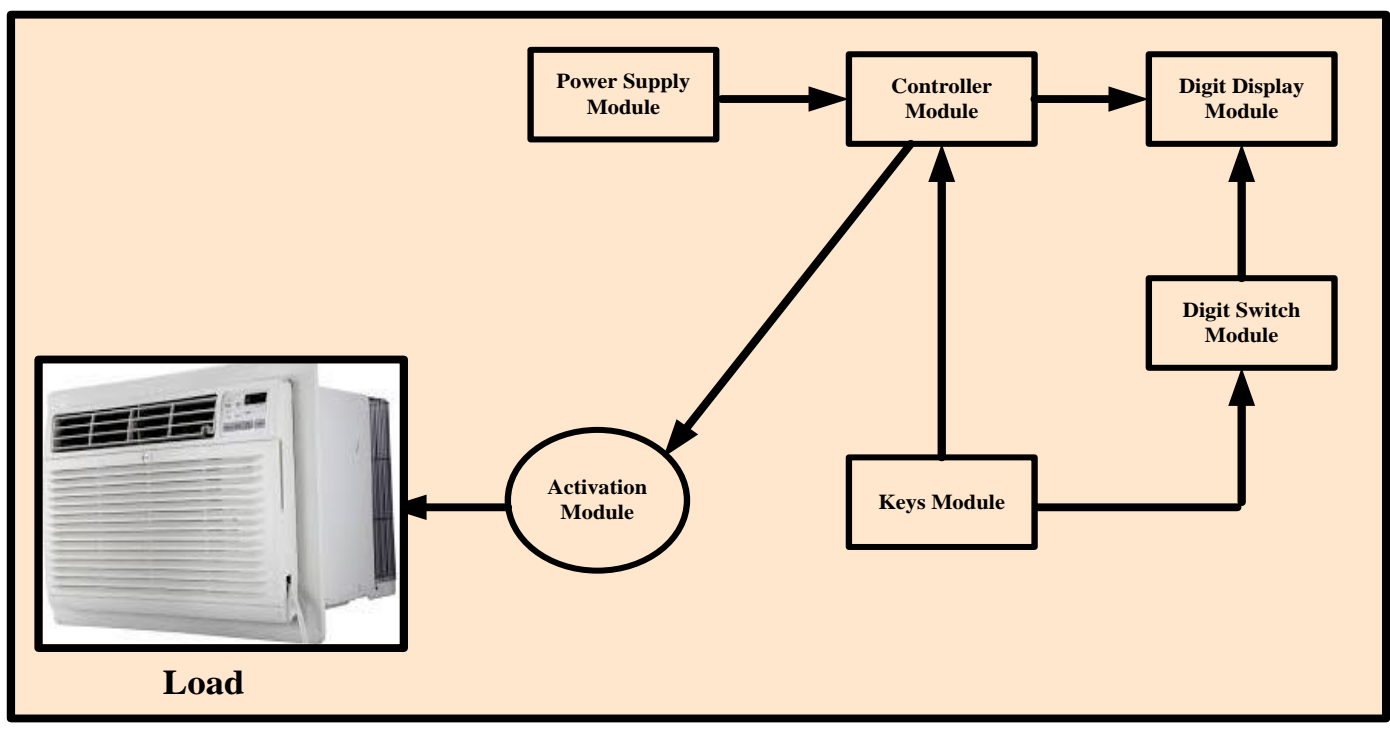

Fig.1. Overview block diagram

\section{1) Power supply module}

This module supplied the regulated voltage to energize the microcontroller and other components. It has two supplies i.e. the AC supply and the DC power supply from the battery. The battery acts as a power backup for the AC supply, in case there is a failure from the main source, (i.e. PHCN). The time settings made by the users are secured and protected from loss by a constant supply of power from the backup battery to the memory of ATMEGA328 chip.
An electronic device and circuits such as this time switching system require a direct current (DC) source for their operation. Dry cells and batteries are forms of DC sources. They have the advantage of being portable and ripple-free. However, the voltages are low; these sources need frequent replacement and are expensive as compared to the conventional DC Power supply. The conventional DC power source was achieved from the main source by converting the AC to DC.

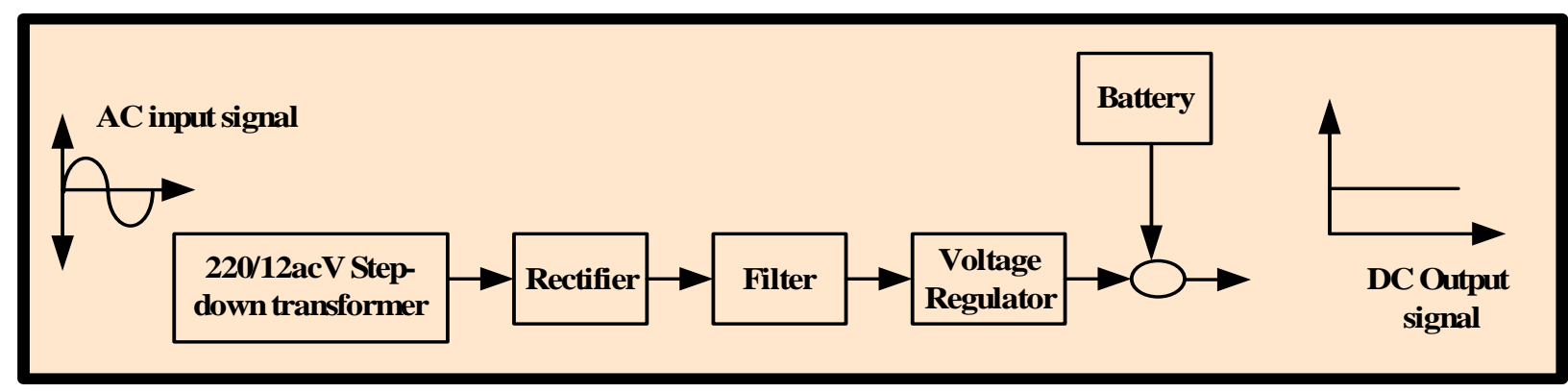

Fig.2. Power supply module

\section{2) Controller module}

This module played a vital role in achieving the objective of this design. All signals flowed IN and OUT of the module as they were early shown in Figure 1 . The module accommodated the instructions/codes (programs), coordinated the electrical activities of sub-circuits, thus; it operated the relay in the activation module and sent corresponding timing setting to the output display for visual understanding.

A reset circuitry consisted of resistor and capacitor connected in parallel via RST pin of the microchip. The connection resets the microchip automatically when booting up. However to get a reset time of less than one (1) second the value of the resistor and the capacitor must be carefully selected. Assume $\mathrm{R}=5 \mathrm{~K}$ and $\mathrm{C}=10 \mu \mathrm{F}$,

$$
\begin{gathered}
\text { Reset Time } \mathrm{T}_{\mathrm{R}}=\mathrm{RC} \\
5 \times 10^{3} \times 10 \times 10^{-6}=5 \mathrm{~ms}
\end{gathered}
$$

The ATMEGA328 operates based on the external crystal connected to its $\mathrm{Xl}$ and $\mathrm{X} 2$ as shown in Figure 5. Effectively, the chip also operates on what is called "machine cycles".

A machine cycle is the minimum amount of time in which a single 8051 cycle can be executed per second by the microchip?

Number of single instruction per second (NSCI)

$$
\mathrm{NSCI}=\frac{\text { Crystal frequency }}{\text { Number of cycle }}
$$


For 1 cycle, 12 pulses.

$$
\mathrm{NSCI}=\frac{12,000,000}{12}
$$

This means that the ATMEGA328 can execute 1M single-cycle instruction per second. For 2-cycles instruction, the microchip would execute 500,000 instruction/ second.

\section{3) Digit display module}

This module displayed the ON or OFF time. It comprised of four seven-segment displays. Any adjustment in time setting was displayed for user's confirmation.

Let calculate the switching current of each transistor connected to the LEDs. Let one segment represents all the 7-segments of each LED as shown below:

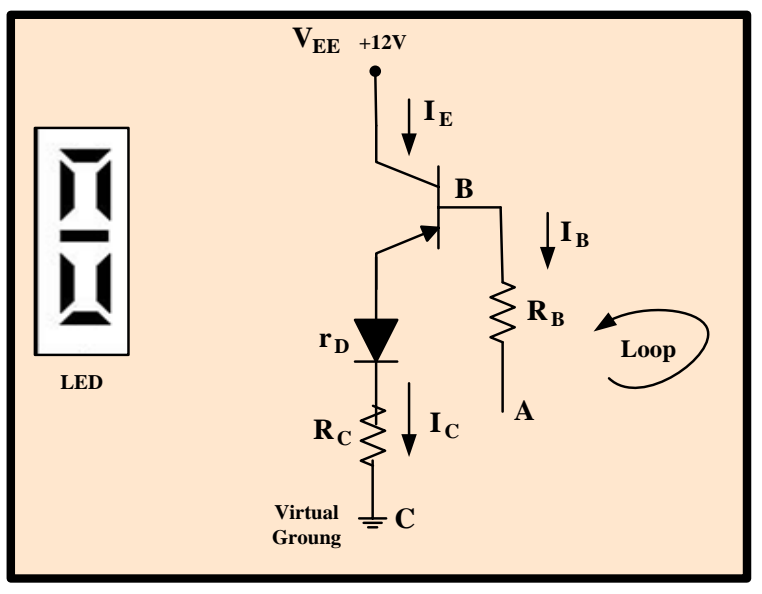

Fig.3.LED driver

From the circuit, the emitter current, $\mathrm{l}_{\mathrm{E}}$ can be evaluated as follows;

$$
\begin{gathered}
\mathrm{V}_{\mathrm{EE}}-\mathrm{V}_{\mathrm{EB}}-\mathrm{L}_{\mathrm{B}} \mathrm{R}_{\mathrm{S}}=0 \\
\mathrm{I}_{\mathrm{E}}=\mathrm{V}_{\mathrm{EE}}-\mathrm{V}_{\mathrm{BE}}
\end{gathered}
$$

where $R_{S}=R_{C}+r_{D}$, neglecting $V_{B E}, r_{D}$ is diode resistance

$$
\begin{gathered}
I_{E}=\frac{V_{E E}-V_{B E}}{R_{S}} \\
I_{E}=\frac{12}{R_{S}}
\end{gathered}
$$

To drive the 7 -segment, a maximum of $25 \mathrm{~mA}$ was required as stated in the datasheet of the manufacturer. Therefore, what value of $R_{S}$ would be suited to drive the 7-segment?

Let $l_{\mathrm{E}}=25 \mathrm{~mA}$

$$
R_{S}=\frac{12}{25 X 10^{-3}}=480 \Omega
$$

The preferred value would be $480 \Omega$
However, $\mathrm{I}_{\mathrm{C}}=\alpha \mathrm{I}_{\mathrm{E}}$

The $\mathrm{h}_{\mathrm{FE}}$ of $\mathrm{C} 945$ is 700 . i.e. $\beta=700$

$$
\begin{gathered}
\alpha=\frac{\beta}{(1+\beta)} \\
\alpha=\frac{700}{(1+700)}=0.9985
\end{gathered}
$$

From Equation 5,

$$
\mathrm{I}_{\mathrm{C}}=0.9985 \times 25=24.9625 \mathrm{~mA}
$$

The base current, $\mathrm{I}_{\mathrm{B}}$ can be calculated as;

$$
\begin{aligned}
\mathrm{I}_{\mathrm{B}} & =\frac{\mathrm{I}_{\mathrm{C}}}{\beta} \\
=\frac{24.9625}{(700)} & =0.03566 \mathrm{~mA}
\end{aligned}
$$

What value of $R_{B}$ makes $I_{B}=0.03566 \mathrm{~mA}$ ?

Applying Kirchhoff's Voltage Law to the loop ABC;

$$
\begin{gathered}
\mathrm{I}_{\mathrm{B}} \mathrm{R}_{\mathrm{B}}-\mathrm{V}_{\mathrm{B}} \mathrm{c}-\mathrm{I}_{\mathrm{C}} \mathrm{R}_{\mathrm{S}}=0 \\
\mathrm{I}_{\mathrm{B}} \mathrm{R}_{\mathrm{B}}=\mathrm{V}_{\mathrm{BC}}+\mathrm{I}_{\mathrm{C}} \mathrm{R}_{\mathrm{S}}
\end{gathered}
$$

but

$$
\begin{gathered}
\mathrm{I}_{\mathrm{C}} \mathrm{R}_{\mathrm{S}}=0.0249625 \times 480=11.982 \mathrm{v} \\
\left(\mathrm{R}_{\mathrm{B}} \equiv \frac{\mathrm{V}_{\mathrm{EE}}}{\mathrm{I}_{\mathrm{B}}} ; \text { if } \mathrm{V}_{\mathrm{BC}} \text { is neglected }\right) \\
\mathrm{R}_{\mathrm{B}}=\frac{11.982}{0.03566} \\
\mathrm{R}_{\mathrm{B}}=336.007 \mathrm{~K}
\end{gathered}
$$

Thus, to drive the 7 -segmets;

$$
\begin{gathered}
\mathrm{I}_{\mathrm{S}}=7 \times \mathrm{I}_{\mathrm{C}} \\
=7 \times 24.9625=174.7375 \mathrm{~mA}
\end{gathered}
$$

Consider the 4-LEDs (7-segments), the maximum current required to drive them can be estimated as;

$$
\begin{gathered}
\mathrm{I}_{\mathrm{S}(\max )}=4 \times \mathrm{l}_{\mathrm{s}} \\
=4 \times 174.7375 \\
=698.95 \mathrm{~mA}
\end{gathered}
$$

\section{4) Digit switch module}

This module supplied and controlled the current from the microcontroller chip to each display, amplified the voltage and provided a better transfer characteristic function between the microcontroller and the timer display module. This module assisted the digital display module to increase its driving capabilities.

\section{5) Keys module}

This module allowed the user to set the ON and OFF time of the load connected to the output to the developed time switching system. There were four keys to be pressed to set the desired time. The user could as well interrupt the already set time manually if desired. 


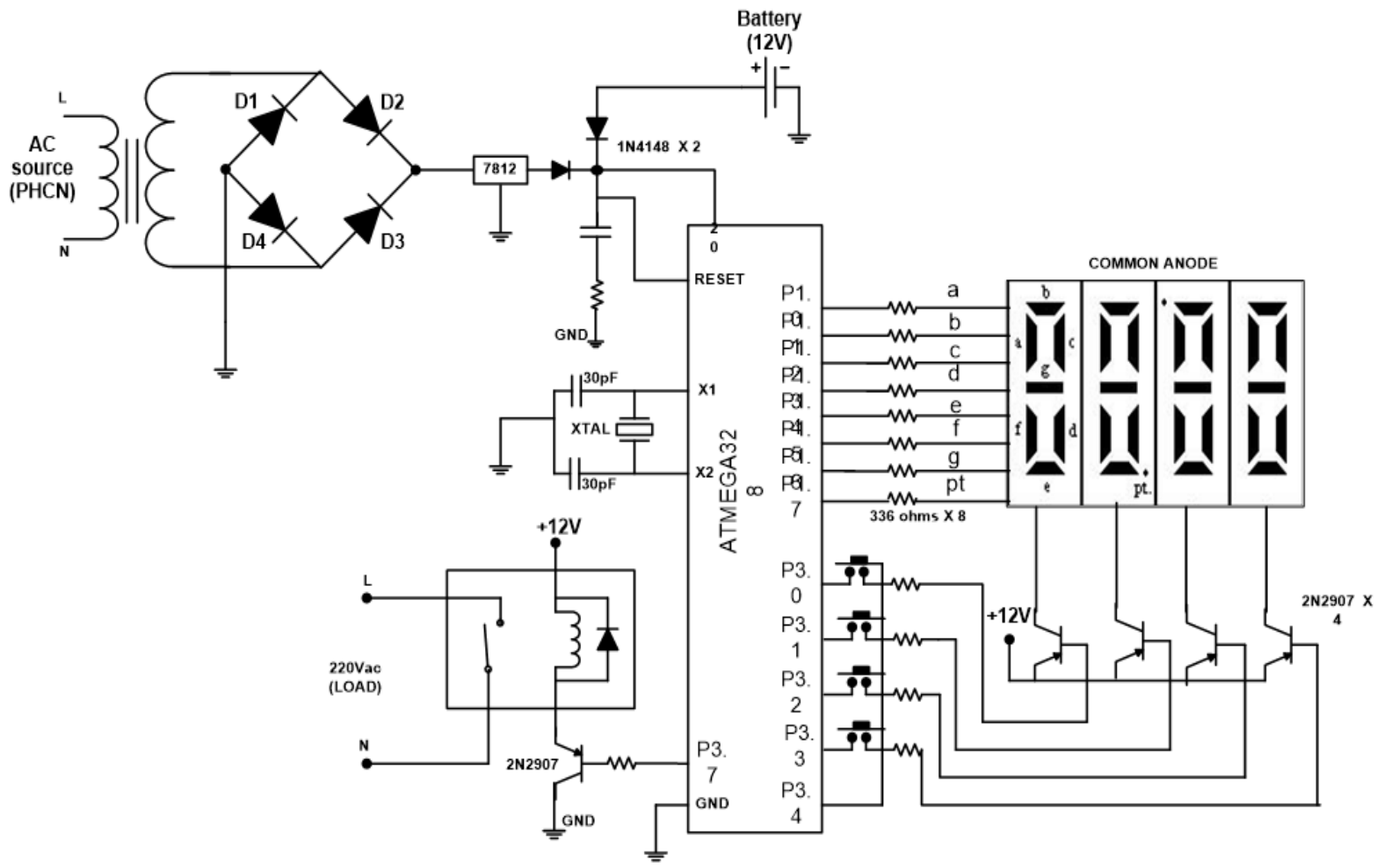

Fig.5.Circuit diagram of the developed system

\section{6) Activation module}

The module had a relay that activated or deactivated any electrical appliance based on the pre-set time. A pulse generated by the microcontroller from its output pin (p3.7) determined if a relay was to be energized or deenergized as instructed by the programs/codes and the time settings by the user.

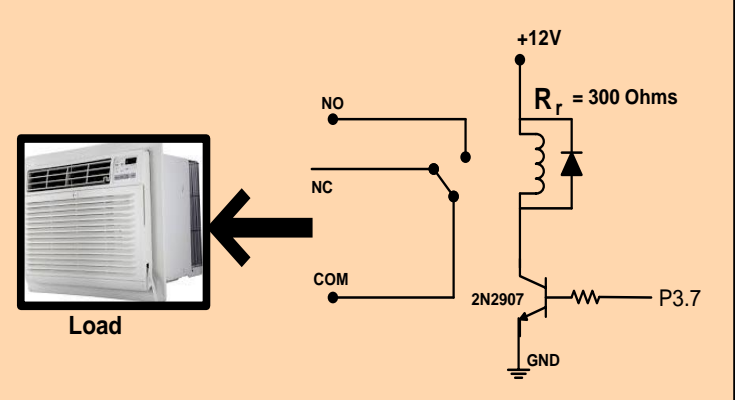

Fig.4. Relay driver

To energize the relay,

$$
V_{C C}-I_{C} R_{r}-V_{C}=0
$$

Where $R_{r}$ is relay coil resistance, $300 \Omega$ or $0.3 \mathrm{~K} \Omega$

$$
\mathrm{V}_{\mathrm{C}}=\mathrm{V}_{\mathrm{CC}}-\mathrm{I}_{\mathrm{C}} \mathrm{R}_{\mathrm{C}}
$$

But,

$$
V_{C E}=V_{C}-V_{E}
$$

Thus,

$$
\begin{gathered}
V_{C E}=V_{C C}-I_{C} R_{r}-V_{E} \\
V_{C E}=V_{C C}-I_{C} R_{r} \quad\left(I_{E} R_{E}=V_{E}=0\right) \\
=12-24.9625 \times 0.3 \\
=4.511 \mathrm{~V}
\end{gathered}
$$

From

$$
V_{C E}=V_{C C}-I_{C} R_{r}
$$

At saturation; $\mathrm{V}_{\mathrm{CE}}=0$;

$$
\mathrm{I}_{\mathrm{C}(\mathrm{sat})}=\frac{12-0}{0.3}=40 \mathrm{~mA}
$$

At cut-off; $\mathrm{I}_{\mathrm{C}}=0$;

$$
\begin{gathered}
0=\frac{12-\mathrm{V}_{\mathrm{CE}(\text { Cut }- \text { off })}}{0.3} \\
V_{C E(\text { Cut }- \text { off })}=V_{C C}=12 \mathrm{~V}
\end{gathered}
$$

Therefore, to energize the relay, $\mathrm{Ic}_{(\mathrm{sat})}$ is the required current. The load line graph is showing below. Where $\mathrm{Q}$ $(12 \mathrm{~V}, 40 \mathrm{~mA})$ is the quiescent point. The point represents the values of $I_{C}$ and $V_{C E}$ that existed in the transistor when no input signal is applied. 


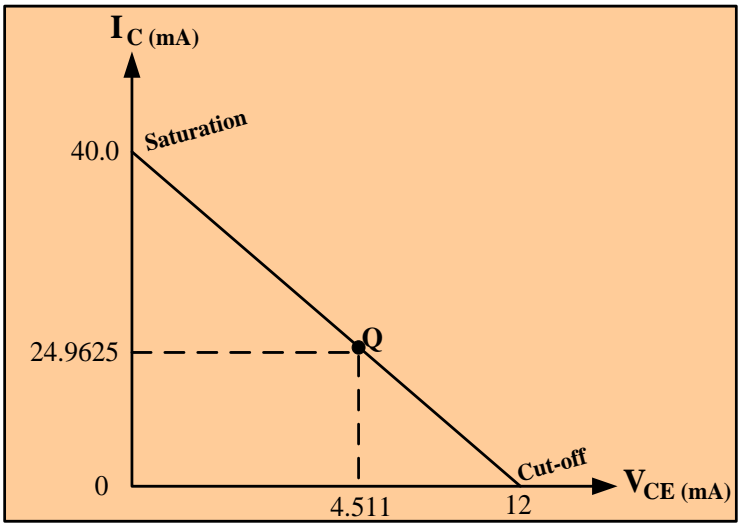

Fig.6. Load graph

Figure 5 shows complete circuit diagram of a developed time switching system.

\section{B. Software Development}

The operations of developed switching system were programmed in $\mathrm{C}$ language. The $\mathrm{C}$ codes were compiled and edited using Crimson editor and the edited codes were transferred into Small Device C Compiler (SDCC) to compile the source codes into HEX CODES needed by the chip for proper execution. The HEX codes were transferred into the memory of the microcontroller.

Figure 7 shows the screenshots of the developed time switching system.

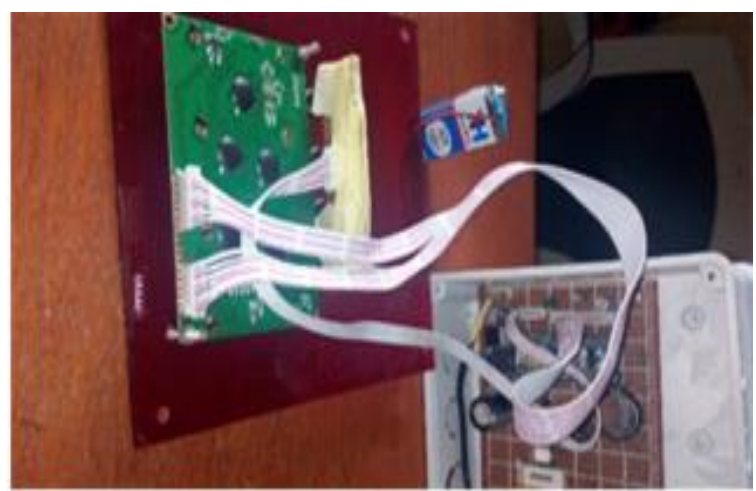

Fig.7. Screenshot of the developed system

\section{TESTING AND EXPERIMENTAL RESUltS}

A proper connection of the required components was made and the developed system was powered and it worked as expected. Each module was tested and the results indicated a perfect operation. The activation module was tested with a battery backup and the signal received was impressive. Electrical load was connected and a user was permitted to input a time signal to the developed system. Based on the user's pre-set ON and OFF times, the electrical load connected was activated and de-activated as instructed. Additionally, the developed switching system was tested and the experimental results of the research are shown below.
Table 1. Experiment 1-Testing and Results

\begin{tabular}{|l|l|l|l|}
\hline Test & Testing & Description of tests & Results \\
\hline 01 & $\begin{array}{l}\text { Testing } \\
\text { backup } \\
\text { battery }\end{array}$ & $\begin{array}{l}\text { The PHCN source } \\
\text { was disconnected to } \\
\text { test if the backup } \\
\text { battery was } \\
\text { connected with the } \\
\text { ATMEGA328 chip }\end{array}$ & $\begin{array}{l}\text { The } \\
\text { ATMEGA328 } \\
\text { chip activated the } \\
\text { seven segment } \\
\text { display }\end{array}$ \\
\hline 02 & $\begin{array}{l}\text { Testing } \\
\text { User keys }\end{array}$ & $\begin{array}{l}\text { The four users keys } \\
\text { were tested to set the } \\
\text { time to 7:15 and later } \\
\text { changed to 4:03 }\end{array}$ & $\begin{array}{l}\text { The seven } \\
\text { segments } \\
\text { displayed the time }\end{array}$ \\
\hline 03 & ON testing & $\begin{array}{l}\text { The time 3:19 was } \\
\text { set to activate the air } \\
\text { conditioning }\end{array}$ & $\begin{array}{l}\text { The air } \\
\text { conditioning was } \\
\text { ON at exactly } \\
3: 19\end{array}$ \\
\hline 04 & OFF testing & $\begin{array}{l}\text { The time 5:57 was } \\
\text { set to de-activate the } \\
\text { air conditioning }\end{array}$ & $\begin{array}{l}\text { The air } \\
\text { conditioning was } \\
\text { OFF at exactly } \\
\text { 5:57 }\end{array}$ \\
\hline
\end{tabular}

Table 1 shows testing and results obtained when the developed time switching was connected to air conditioning system. However, Table 2 shows testing and results obtained when the developed time switching was connected to electrical fan to control the switching $\mathrm{ON}$ and OFF times as desired by the user.

Table 2. Experiment 2-Testing and Results

\begin{tabular}{|l|l|l|l|}
\hline Test & Testing & Description of tests & Results \\
\hline 03 & ON testing & $\begin{array}{l}\text { The time 7:57 was set } \\
\text { to activate the } \\
\text { electrical fan }\end{array}$ & $\begin{array}{l}\text { The electrical fan } \\
\text { was ON at exactly } \\
7.57\end{array}$ \\
\hline 04 & OFF testing & $\begin{array}{l}\text { A time of 11.06 was } \\
\text { set for switching OFF }\end{array}$ & $\begin{array}{l}\text { The electrical fan } \\
\text { was OFF at } \\
\text { exactly 11.06 }\end{array}$ \\
\hline
\end{tabular}

In comparative analysis of the findings and results, a switching time of $0.88 \mathrm{~ms}$ was obtained in [9]. However, this new time switching system had $0.0 \mathrm{~ms}$ as the switching ON and OFF was instance without any delay. A value of $0.88 \mathrm{~ms}$ might not humanly significant, but technically and economically the value is significant in electrical management. With $0.88 \mathrm{~ms}$, about $0.0013 \mathrm{KW}$ could be wasted in 1 day which is not economically good.

Table 3. Results Comparison

\begin{tabular}{|l|c|c|c|c|}
\hline Parameters & Ref [10] & Ref [12] & Ref [15] & $\begin{array}{l}\text { Developed } \\
\text { system }\end{array}$ \\
\hline $\begin{array}{l}\text { Carrying } \\
\text { current }\end{array}$ & $57 \mathrm{~A}$ & $48 \mathrm{~A}$ & $45.83 \mathrm{~A}$ & $\begin{array}{c}24.9625 \mathrm{~m} \\
\mathrm{~A}\end{array}$ \\
\hline $\begin{array}{l}\text { Required } \\
\text { voltage }\end{array}$ & $210.53 \mathrm{~V}$ & $245.55 \mathrm{~V}$ & $193.32 \mathrm{~V}$ & $4.511 \mathrm{~V}$ \\
\hline $\begin{array}{l}\text { Active } \\
\text { power }\end{array}$ & $12 \mathrm{KW}$ & $11.86 \mathrm{KW}$ & $8.86 \mathrm{KW}$ & $0.1126 \mathrm{~W}$ \\
\hline
\end{tabular}

Table 3 shows a comparison on the carrying current capacity, required voltage and active power for [10], [12], [15] and the newly developed time switching system. Table 3 further indicates drastically reduction in the power consumption of [10], [12] and [15] to 0.01126 watt. By implication, application of this newly developed time switching system would eliminate electrical signal wastage thereby increasing income for maximum 
productivity. The cost of electricity bill would be technically reduced with this new time switching.

Furthermore, an electric kettle was connected to the output of the developed switching system. A switching time of 2.07 was pre-set to automatically switch ON the kettle and 4.11 were pre-defined to switch OFF the kettle. The kettle was left on observation and findings at the desired times. The experimental results indicated that at exactly 2.07 and 4.11 of pre-set times for ON and OFF times, the power supply was regulated as desired with no electrical power wastage recorded.

\section{CONCLUSION}

The core technologies of the developed system involved the application of a microcontroller to control the switching times of any electrical appliances as desired by the users. There was a power supply to the microcontroller and instructions based on the user's times set, were executed by the controller through a corresponding signals to the activation module where the electrical appliance was connected. The relay in the activation module was either activated or de-activated to switch ON or OFF of the appliance. As user pre-set or pre-defined the times for $\mathrm{ON}$ and $\mathrm{OFF}$, the instructions were stored in the memory of the microcontroller for corresponding actions.

The research was focused on designing and implementation of a time switching system using the Atmega328 microcontroller. The circuit was designed, simulated and soldered using the identified electronic components and values. The codes were written, compiled into HEX file and transferred into the memory of the microcontroller. The developed switching system was tested and satisfactorily switched ON and OFF air conditioning as desired and pre-set by the user. With all these experimental results, it would be concluded that the objectives of this research had been achieved as the times to switch $\mathrm{ON}$ and $\mathrm{OFF}$ of electrical appliances were technically controlled and electrical power wastage was solved.

\section{ACKNOWLEDGEMENT}

This research was sponsored by the Tertiary Education Trust Fund (TETFUND) under the intervention of Institution Based Research (IBR) that offers a specific solution to a specific problem.

\section{REFERENCES}

[1] F. M. Abu, H. M. Fida, M. I. Manirul and A. Mohiuddin., "Microcontroller Based Remote Control of Home Appliances," Proceeding of the International Conference on Electrical, Computer and Telecommunication Engineering, held at Bangladesh in December 2012, pp. $511-514$

[2] S. Aditi, P. Priyanka, N. Kanchan and S. Shital, "Clap Pattern Based Electrical Appliance Control", International Research Journal of Engineering and Technology (IRJET),2017, vol. 4(2), pp. 902-905.
[3] R. Chintha, P. O. Benny, O. Vijaylaxmi, D. Varsha and B. S. Prasad", Electrical appliances in home control through IR Remote," International Journal of Innovative Research in Technology (IJIRT), 2017, vol. 3(9), pp. 16-19.

[4] G. K. Jonathan and S. D. Umar, "Development of a simple programmable control timer," Leonardo Journal of Sciences, 2008, vol. 12, pp. 175-186

[5] W. Niti and N. Pongpon, "The Development of Smart Home System for Controlling and Monitoring Energy Consumption using WebSocket Protocol," Materials Science and Engineering, 2017, pp. 1-6.

[6] J. Morgan, "Time Management. Mood House Press, California, 2009

[7] E. A. Salako, "Introduction to BASIC Programming Language," MAT-Sunshine Prints: Abuja, Nigeria, 2017.

[8] A. Amevi, M. A. Michael and A. Noble "Design, testing and analysis of single phase electronic changeover with security light," APT Journal of Multidisciplinary Research, 2016, vol. 1(1), pp. 17-24.

[9] O. Bamidele, J. Samuel and O. Omakoji, "Developing an Automatic Switch for Home or Industrial Power Supply Changeover," British Journal of Applied Science \& Technology, vol. 21(4), pp. 1-7

[10] E. Idoko, P. I. Udenze and F. T. Ikule "Design and implementation of three phases automatic change over switch," International Journal of Advanced Engineering Research and Technology (IJAERT), 2018, 6(7), 435-439.

[11] L. S. Ezema, B. U. Peter and O. O. Harris, O. O. "Design of Automatic Change-Over Switch with Generator Control Mechanism". Electrical Power and Electronic Development, Department Projects Development Institute, 2012, vol. 3 (3), pp. 125-130.

[12] A. R. Atser, F. N. Gesa, and I. S. Aondoakaa, "Design and Implementation of a 3-Phase Automatic Power Changeover Switch," American Journal of Engineering Research, 2014, vol. 3 (9), pp. 7-14.

[13] [C. A. Osaretin, E. I. Ibhadode and S. O. Igbinovia, "Design and implementation of automatic changeover switch (with step loading) for renewable energy Systems. International Journal for Renewable Energy and Environment, 2016, vol. 2, pp. 179-192.

[14] T. Ilomuanya and U. V. Okpala, "Implementation of the Designed Automatic Change Over System for the Department of Physics, Chukwuemeka Odumegwu Ojukwu University, Uli. International Journal of New Technology and Research, 2016, 2 (4), pp. 130-136.

[15] O. M. Okome and O. Folorunso, "Automatic transfer switch with three phase selector," International Journal of Scientific \& Engineering Research, 2015, vol. 6 (7), pp. 81-87.

[16] A. F. Agbetuyi, A. A. Adewale, J. O. Ogunluyi and D. S. Ogunleye, "Design and construction of an automatic transfer switch for a three phase power generator. International Journal of Engineering Science, 2014, vol 3, pp 57-66

Author's Profile

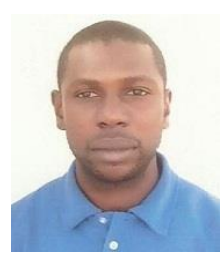

Salako Emmanuel Adekunle received a degree (B.Eng) in Electrical and Computer Engineering, Master of Technology (M.Tech) in Computer Science from Federal University of Technology, Minna, Niger State. He is currently undergoing his $\mathrm{PhD}$ at the Federal University of Technology, 
Akure, Nigeria. $\mathrm{He}$ is a lecturer at Computer Science Department FCT, College of Education, Zuba. His research interests include Biometric Security, Educational Technology and Control Technology. He has published papers in reputable local and international journals and his published textbooks included Introduction to Computer Logic, Learning Pascal Made Easy and BASIC Programming Language. He is a member of the Nigeria Computer Society.

How to cite this paper: Salako Emmanuel Adekunle, "A Time Switching System Using Atmega328 Microcontroller towards Solving Problem of Electrical Power Wastage", International Journal of Image, Graphics and Signal Processing(IJIGSP), Vol.11, No.6, pp. 18-26, 2019.DOI: 10.5815/ijigsp.2019.06.03 